Association for Information Systems

AIS Electronic Library (AISeL)

2018 Proceedings

Portugal (CAPSI)

2018

\title{
A demonstration of an application of the Bertrand Network: Guessing the distribution of buyers within the market
}

\author{
Murillo Henrique Pedroso Ferreira \\ Polytechnic Institute of Bragança, murillo.hpf@gmail.com \\ João Paulo Pereira \\ Polytechnic Institute of Bragança, jprp@ipb.pt
}

Follow this and additional works at: https://aisel.aisnet.org/capsi2018

\section{Recommended Citation}

Ferreira, Murillo Henrique Pedroso and Pereira, João Paulo, "A demonstration of an application of the Bertrand Network: Guessing the distribution of buyers within the market" (2018). 2018 Proceedings. 1.

https://aisel.aisnet.org/capsi2018/1 


\title{
A demonstration of an application of the Bertrand Network: Guessing the distribution of buyers within the market
}

\author{
Murillo Henrique Pedroso Ferreira, Polytechnic Institute of Bragança, Portugal, \\ murillo.hpf@gmail.com \\ João Paulo Pereira, Polytechnic Institute of Bragança and UNIAG (Applied Management Research \\ Unit), Portugal, jprp@ipb.pt
}

\begin{abstract}
Bertrand and the Cournot model are one of the most used model for modeling competition between companies. This paper presents a work-in-progress that studies the application of the recently developed Bertrand Network model by using it in a reverse manner: first it is considered that firms are competing in equilibrium, then, after analyzing how companies are choosing prices, it is calculated which distribution of buyers would lead to that equilibrium. An unreal example is presented to help to understand the model. Furthermore, a formula is suggested to expand the networked model to allow a mix of duopolies and oligopolies.
\end{abstract}

Keywords: nash equilibrium; bertrand network; market competition; expanded bertrand network; market expansion

\section{INTRODUCTION}

In the last years there have been researches to expand the classic Cournot and Bertrand market model to one version that considers a network competition, where firms can compete over different markets against different firms at the same time (Bose S. et al 2014; Motalleb et al 2017; Abolhassani et al, 2014). Recent models expanded the idea of a single oligopoly model, where multiple firms compete for one market share (Bimpikis et al, 2014), since nowadays companies are even able to compete in multiple markets and react in real-time due to online analysis tools (Babaioff, et al, 2014).

Antoine Augustin Cournot and Joseph Bertrand have introduced the first model for studying the duopoly competition where. In the first one, firms can only choose quantity of a good to supply to the market (leaving the price to be determined by an auctioneer (Scheinkman \& A., 1983)), while in the second one, firms can choose price as a strategy (Abolhassani et al, 2014).

Both tools have been used for investigating competitive markets, while Bertrand model are more suitable for price competition (Babaioff et al, 2014; Kasbekar \& Sarkar, 2012). Cournot competition is being used for modeling markets like electricity, where vendors decide for quantities rather than prices (Abolhassani et al, 2014), e.g., (Barquin \& Vazquez, 2008; Jing-Yuan \& Smeers, 1999; Yao, Oren, \& Adler, 2004). The Bertrand Network model has been proposed by Guzmán (2011) and it has been expanded in other works (Babaioff et al, 2013; Babaioff et al, 2014; Babaioff et al, 2016). 
All of them being an expansion of the classic model that has been widely used in pricing competition (Babaioff et al, 2014).

In the existing Cournot Network Competition (Bimpikis et al, 2014), an arbitrary number of firms can compete in the same market. This model allows to predict the reaction of other firms in case of one vendor decides to join one existing market share, as well as predict whether it is profitable for two firms to merge or not.

The main field of study of the authors is to offer a tool to analyze the chance of success to one vendor if he tries to expand to another market, in special, expanding to a market in another country (an international expansion). In the study, firms are competing using prices in several markets. The authors are currently working in another improvement for the Bertrand Networked Model (Babaioff et al, 2013), which contains several profs that asserts the existence of a Nash Equilibrium in any graph but has a limitation: only two firms can compete against each other in the same shared market. In the existing model, all buyers in each market share buy from the firm that asked for the lowest price. Firms cannot price discriminate, which means that each of them will ask for the same price for both shared markets that they are participating in and the captive market (if he has one). It is assumed that all companies sell a homogeneous good, so buyers are only interested in the lowest price (these properties have been kept).

The goal is to allow more firms to compete for one market. Since the main field of study is to evaluate whether is it profitable for a firm to join an existing market or not, it is required to allow at least 3 vendors to compete at the same market share (the firm that wants to expand, as well as two others that were already competing), which is not possible in the existing model. The attempt to expand the existing model uses the same basic structure: a hypergraph where each node represents firms, and hyperedges that represents shared markets. In addition, it is currently being worked on a practical application of the Bertrand Network model for this study, which is believed to be from little to no work that used the model that has inspired this work, in contrast to the Cournot Network model., e.g., (Bose S et al, 2014; Cai et al, 2017; Motalleb et al, 2017).

This paper presents one of the possible applications of the existing model to verify why companies are pricing in one specific way. Furthermore, it is shown one more evidence that, for each oligopoly market in the Expanded Bertrand Network, each vendor does not do better than ignoring the existing of such market share since the competition will be too aggressive between the two small vendors, as has already been proved by Guzmán (2011).

The remainder of this paper is structured as follows. Section 2 shows the Bertrand Network model, to understand its structure. Since there is a lack of a practical usage of the Bertrand Network in a real case, Section 3 presents how to apply the existing model in a real scenario. The Section 4 shows 
an expanded formula from the existing model, that is, Equation (7), as well as an illustrative example to better understand the formula, leaving the remaining section for discussion of the future work.

\section{EXISTING MODEL}

This warm-up example will be useful to understand the structure of the Bertrand Network. Consider the following competition among three vendors: the firm $f_{1}$ sells devices to users that are interested in high-performance and has a captive market $\alpha_{1}=20$ that represents the set of buyers that will buy from the firm $\mathrm{f}_{1}$ no matter the price, as long it is not higher than 1 (loyal buyers). The firm $\mathrm{f}_{2}$, on the other hand, sells devices to buyers that are interested in both high and low performance devices (participating in two different markets). Finally, the firm $\mathrm{f}_{3}$ are only interested to sell to buyers that are interested in low-performance devices. After this, buyers were categorized into three different markets.

The firm $\mathrm{f}_{1}$ competes for the market $\beta_{1,2}=150$ against $\mathrm{f}_{2}$, while the firm $\mathrm{f}_{3}$ competes for the market $\beta_{2,3}=185$ against $f_{2}$. Neither $f_{2}$ nor $f_{3}$ has a set of loyal buyers, therefore, $\alpha_{2}=\alpha_{3}=0$.

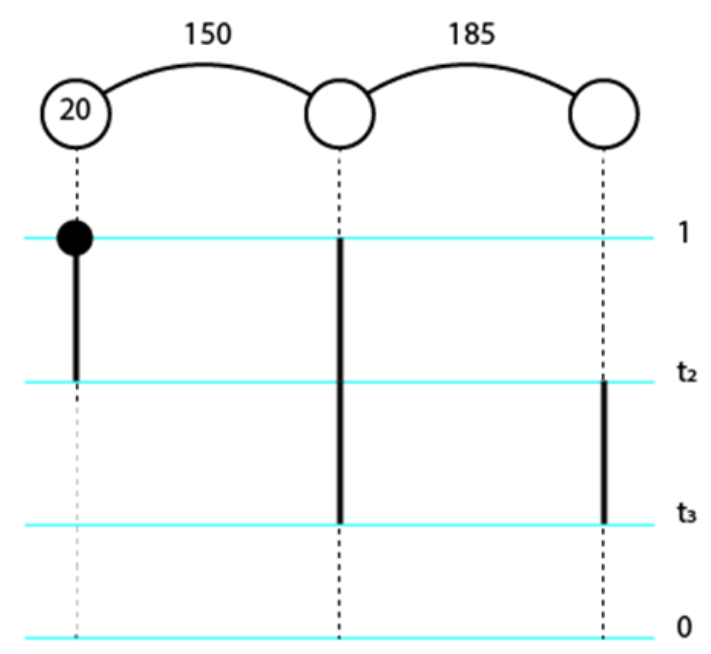

Figure 1 - Example of competition. Nodes represent firms, each hyperedge represents a market share. Captive markets are represented with a weight within the node, in which an empty node represents a captive market of size zero. Thick lines represent the pricing strategy of each firm that falls within their support, as a subset of $[0,1]$. The black circle represents an atom at 1 . It is said that when a firm has an atom at 1 , the firm chooses the price of 1 with a positive probability.

In the given example, $f_{1}$ faces a tradeoff between extracting the maximum surplus from its captive market by asking for the monopolized price of 1 and lowering the price to increase the likelihood of 
winning market share $\beta_{1,2}$. On the other hand, $f_{2}$ must decide for a price that, at the same time, will extract the maximum surplus from both shared markets.

Figure. 1 shows the competition network and the equilibrium sketch for the network. An equilibrium sketch is defined as a specification of the finitely bounded pricing range (support) for every seller $\mathrm{i}$ and the set of sellers that has an atom at 1. (Babaioff et al, 2013) has formally defined it in Definition 5.1 and any support can be set, as well as any set of sellers with an atom at 1 can be chosen, but the results from the equilibrium sketch must satisfy the properties in Definition 5.2.

From the results in Babaioff et al (2013, pp. 7-8), the unique Nash Equilibrium (N.E.) for this topology is that each company must mix its pricing strategy by following its support (see Figure 1) and randomize by following its Cumulative Distribution Function (CDF). To each company be indifferent in choosing any price that falls within its support, the utility level for each vendor must be the same by pricing at $x \in\left[t_{m}, t_{n}\right]$ (where $0<t_{m} \leq t_{n} \leq 1$ are the boundary points of its support, for a network that has at least one firm with an nonzero captive market). Formally, the following must hold:

$$
\begin{gathered}
u_{1}\left(t_{1}\right)=u_{1}\left(t_{2}\right)=u_{1}(x) \forall x \in\left[t_{2}, t_{1}\right] \\
u_{2}\left(t_{1}\right)=u_{2}\left(t_{2}\right)=u_{2}\left(t_{3}\right)=u_{2}(x) \forall x \in\left[t_{3}, t_{1}\right] \\
u_{3}\left(t_{2}\right)=u_{3}\left(t_{3}\right)=u_{3}(x) \forall x \in\left[t_{3}, t_{2}\right]
\end{gathered}
$$

By working with the equalities above, it is possible to find the CDF function that represents the probability of each firm to choose the price of at least $\mathrm{x}$. The utility level of each firm is defined by Babaioff et al (2013) as follows:

$$
u_{i}\left(x, F_{-i}\right)=u_{i}(x)=x\left(\alpha_{i}+\sum_{j \in N(i)} \beta_{i, j} \bar{F}_{j}(x)\right)
$$

Where $N(i)$ is a set of neighbors of $i, \beta_{i, j}$ is the weight of the edge that connects $i$ and $j, \alpha_{i}$ is the size of the captive market of $i$ and $\bar{F}_{j}(x)$ represents the inverse CDF function (CDF for short), the mixed pricing strategy for the firm $\mathrm{j}$. The inverse $\mathrm{CDF}$ is a nonincreasing linear function in $\mathrm{x}^{-1}$ which can be explicitly found for every $\mathrm{x} \in[0,1]$ by working with equalities in (1). For a detailed description of how to find the explicit CDF function for every firm i (for the same graph), see Babaioff et al (2013, pp. 7-8). 
Firms chance to choose the price of at least $x$

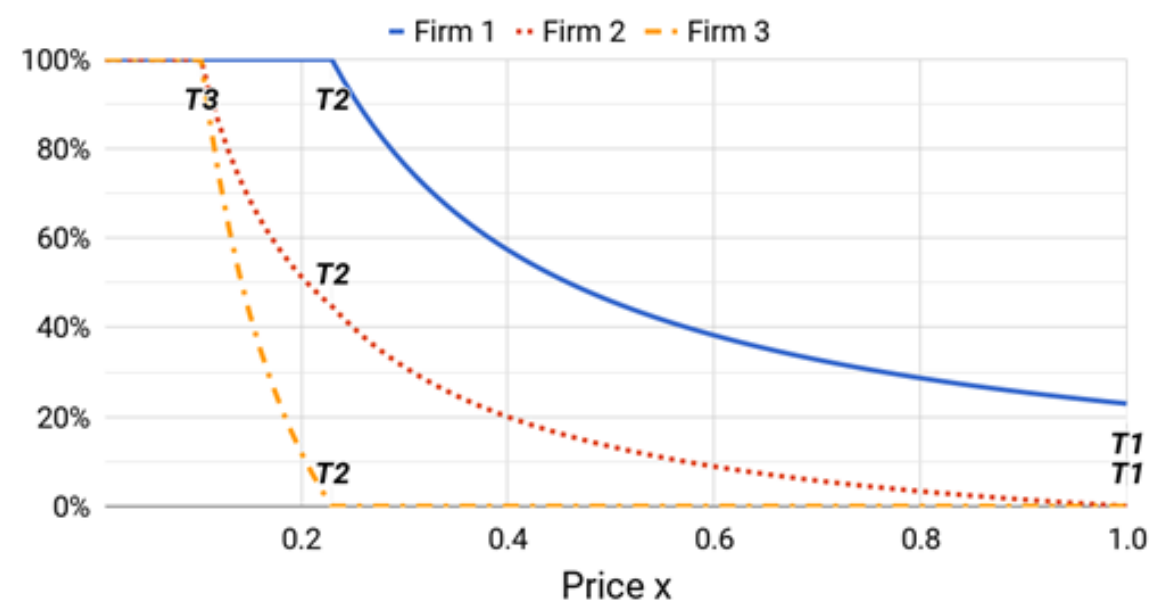

Figure 2 - Optimal Inverse Cumulative distribution function for each firm after working with the equalities defined in Equation (1). This represents the expected behavior for each firm. For instance, Firm 1 has the chance of $100 \%$ of choosing the price of 0.2 for higher, which means that it is not expected to see Firm 1 asking for the price lower than 0.2 .

For this example, by working with the equalities in (1), it has been found that $t_{1}=1, t_{2}=$ 0.2294520548 , and $t_{3}=0.102739726$. Those values are the optimal pricing ranges for each firm $i$ that allows mixing where none of the firms can deviate to another CDF function (pricing strategy) or to another pricing ranges to get a better payoff. In the Figure. 3 , it is possible to see that $f_{2}$ is more likely to succeed in this scenario by having the highest utility level.

\section{Firms utilities by pricing at $X$}

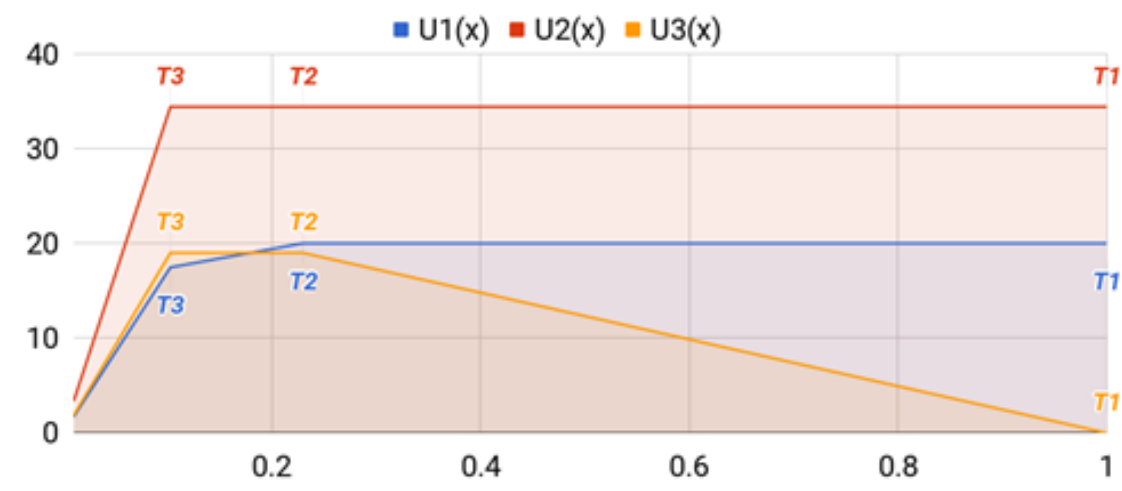

Price $\mathrm{X}$

Figure 3 - Utility level for each company. Note that between the pricing range that fall within the support of each firm, the utility level is the same. 


\section{APPLYING THE MODEL IN A REVERSE MANNER}

To verify if it is profitable for a firm to join an existing market, it is needed to apply this model to one existing network and then, simulate an entrance from some firm (see Fig. 5 for an illustrative example). Comparing the results will show information such as:

- Changes in pricing decision of each firm (reaction);

- Expected profit of each firm before and after the entrance of a firm in the network.

It is important to comprehend how buyers are distributed over market shares. This allows an analyst to understand the potential changes of each market in the network by repeating the process over time, tracking what is happening to the markets. If the result from the model shows that the number of buyers in a market has fallen, it may suggest that the market is in decline.

While the existing Bertrand Network model allows to go from the size of markets to the optimal ranging prices for each company, it is suggested to do the opposite in this study. If the distribution of buyers is not known, it will not be possible to repeat the calculations like the one briefly shown in the Section 2. The remainder of this section shows how to use the model to discover proportion of buyers from each market.

First, one must model the competition network by checking who is competing against whom and in which market. Then, figure out the equilibrium sketch of the built network because it is not known any algorithm that can give the equilibrium of any given network, although the equilibrium sketch is known for some graph structures (Babaioff et al, 2013). Also, a data set of prices is needed, so an information of prices over time is required to known how sellers are pricing.

It is assumed that the companies are playing the price competition game rationally, i.e., are indeed following their best CDF to choose prices within the optimal pricing range.

Recalling the Section 2, the same graph structure is modeled, but now the market sizes are assumed to be unknow and it will be shown that it is possible to get similar results from the original example by only knowing the prices that each firm was choosing.

\subsection{Collecting Prices}

Consider that prices were collected from day $d_{1}$ to $d_{n}$ and let $P_{i, k, j}$ be the $j$-th price from the k-th day of the $\mathrm{i}$-th firm. Let $\mathrm{P}_{\mathrm{i}}$ be the non-decreasing sorted set of prices from the $\mathrm{i}$-th firm. Finally, let $\mathrm{P}$ be the union of every $\mathrm{P}_{\mathrm{i}}$.

As the existing model use prices in $[0,1]$, let the collected prices be mapped from $[0, \mathrm{M}]$ to $[0,1]$, where $\mathrm{M}$ is the highest price collected. Formally, let $\mathrm{f}: \mathrm{P} \rightarrow[0,1]$. 
Recalling the graph presented in the Section 2, the equilibrium sketch defines that the seller $f_{1}$ is pricing in $\left[t_{2}, t_{1}\right], f_{2}$ in $\left[t_{3}, t_{1}\right]$ and $f_{3}$ in $\left[t_{3}, t_{2}\right]$. Therefore, $t_{1}$ must be the greatest value in $P, t_{3}$ the minimum and let $t_{2}$ be the minimum value of $\mathrm{f}_{1}$.

Let $C_{i}(x)$ be the number of elements in $P_{i}$ that are lesser than $\mathrm{x}$. To calculate the probability of randomly choosing the value of $\mathrm{x}$ or higher from the data set, let $\overline{\mathrm{F}}_{\mathrm{i}}(\mathrm{x})=\frac{\left|\mathrm{P}_{\mathrm{i}}\right|-\mathrm{C}_{\mathrm{i}}(\mathrm{x})}{\left|\mathrm{P}_{\mathrm{i}}\right|}$.

\subsection{Assumptions}

Suppose that an analyst has collected a data set that shows the following information:

- $\mathrm{t}_{1}=1$ as it would be in any equilibrium (Babaioff et al, 2013);

- $\mathrm{f}_{1}$ chooses the price of 1 with positive probability (has an atom at 1 ). Consider that after analyzing the data set, it has been found that the probability for $f_{1}$ to choose the price of $t_{1}$ or higher is $\overline{\mathrm{F}}_{1}\left(\mathrm{t}_{1}\right)=0,23$, like in the original example (see Figure. 2 );

- With similar reasoning, $\overline{\mathrm{F}}_{2}\left(\mathrm{t}_{2}\right)=0,45$;

- $\overline{\mathrm{F}}_{1}(\mathrm{x})=\overline{\mathrm{F}}_{2}(\mathrm{x})=\overline{\mathrm{F}}_{3}(x)=1 \forall \mathrm{x} \leq \mathrm{t}_{3}$ since every firm are choosing prices higher than $\mathrm{t}_{3}$;

- $\overline{\mathrm{F}}_{2}\left(\mathrm{t}_{1}\right)=\overline{\mathrm{F}}_{3}\left(\mathrm{t}_{2}\right)=0$ by claiming the results from Babaioff et al (2013, p. 9), Lemma 4.2 that states: "Fix any valid tie breaking rule. In any network and any equilibrium, no two sellers who share a market both have an atom at the same positive price";

- $\overline{\mathrm{F}}_{3}(\mathrm{x})=0 \forall \mathrm{x} \geq \mathrm{t}_{2}$ since $\mathrm{t}_{2}$ is the higher price for $\mathrm{f}_{3}$.

Note that the CDF for each company has been defined at the boundary points in their support, which would be possible by observing a data set. 


\subsection{Calculating the market share from prices and CDFs}

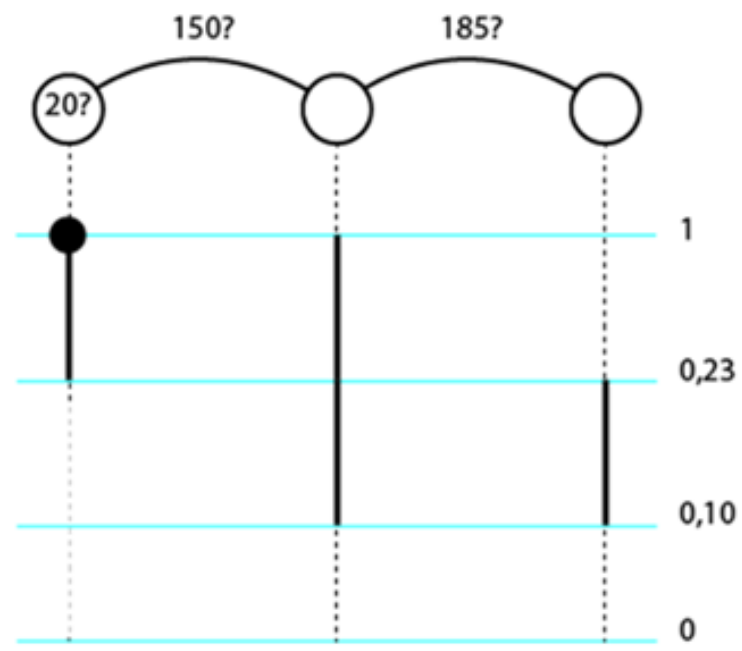

Figure 4 - Hypergraph in which only the prices are known. Note the question marks, indicating that the market sizes are unknown.

Now, the calculation must be started by defining the following equalities that in equilibrium must be satisfied (see Equation (1)).

$$
\begin{gathered}
\mathrm{u}_{1}\left(\mathrm{t}_{1}\right)=\mathrm{u}_{1}\left(\mathrm{t}_{2}\right) \\
\mathrm{t}_{1} * \alpha_{1}=\mathrm{t}_{2} *\left(\alpha_{1}+\beta_{1,2} * \overline{\mathrm{F}}_{2}\left(\mathrm{t}_{2}\right)\right) \\
\frac{\mathrm{t}_{2}}{\mathrm{t}_{1}}=\frac{\alpha_{1}}{\alpha_{1}+\beta_{1,2} * \bar{F}_{2}\left(\mathrm{t}_{2}\right)} \\
\mathrm{t}_{1}\left(\alpha_{2}+\beta_{1,2} * \overline{\mathrm{F}}_{1}\left(\mathrm{t}_{1}\right)\right)=\mathrm{t}_{2}\left(\alpha_{2}+\beta_{1,2}\right) \\
\frac{\mathrm{t}_{2}}{\mathrm{t}_{1}}=\frac{\alpha_{2}+\beta_{1,2} * \overline{\mathrm{F}}_{1}\left(\mathrm{t}_{1}\right)}{\alpha_{2}+\beta_{1,2}} \\
\mathrm{t}_{2} *\left(\mathrm{t}_{1}\right)=\mathrm{u}_{2}\left(\mathrm{t}_{2}\right) \\
\frac{\mathrm{u}_{2}\left(\mathrm{t}_{2}\right)=\mathrm{u}_{2}\left(\mathrm{t}_{3}\right)}{\mathrm{t}_{2}}=\frac{\alpha_{2}+\beta_{1,2}}{\alpha_{2}+\beta_{1,2}+\beta_{2,3}} \\
\left.\mathrm{t}_{3}+\beta_{1,2}+\beta_{2,3}\right)
\end{gathered}
$$




$$
\begin{gathered}
\mathrm{u}_{3}\left(\mathrm{t}_{2}\right)=\mathrm{u}_{3}\left(\mathrm{t}_{3}\right) \\
\mathrm{t}_{2} *\left(\alpha_{3}+\beta_{2,3} * \overline{\mathrm{F}}_{2}\left(\mathrm{t}_{2}\right)\right)=\mathrm{t}_{3} *\left(\alpha_{3}+\beta_{2,3}\right) \\
\frac{\mathrm{t}_{3}}{\mathrm{t}_{2}}=\frac{\alpha_{3}+\beta_{2,3} * \overline{\mathrm{F}}_{2}\left(\mathrm{t}_{2}\right)}{\alpha_{3}+\beta_{2,3}}
\end{gathered}
$$

To be able to calculate the proportion of each market, the following equalities will be used:

$$
\begin{aligned}
\alpha_{1} & =a * \beta_{1,2} \\
\alpha_{2} & =b * \beta_{1,2} \\
\alpha_{3} & =c * \beta_{1,2} \\
\beta_{2,3} & =k * \beta_{1,2}
\end{aligned}
$$

This will simplify the calculations since now it will be possible to find the ratio of each market over $\beta_{1,2}$ (chosen by convenience, note that every shared market will be greater than 0 , otherwise that market share would not exist). From Equation (3):

$$
\begin{gathered}
\mathrm{t}_{2}=\frac{\mathrm{a} * \beta_{1,2}}{\mathrm{a} * \beta_{1,2}+\beta_{1,2} * \overline{\mathrm{F}}_{2}\left(\mathrm{t}_{2}\right)} \\
\mathrm{t}_{2}=\frac{\mathrm{a}}{\mathrm{a}+\overline{\mathrm{F}}_{2}\left(\mathrm{t}_{2}\right)} \\
\mathrm{a}=\mathrm{t}_{2} *\left(\mathrm{a}+\overline{\mathrm{F}}_{2}\left(\mathrm{t}_{2}\right)\right) \\
\mathrm{a}-\mathrm{t}_{2} * \mathrm{a}=\mathrm{t}_{2} * \overline{\mathrm{F}}_{2}\left(\mathrm{t}_{2}\right) \\
\mathrm{a}=\frac{\mathrm{t}_{2} * \overline{\mathrm{F}}_{2}\left(\mathrm{t}_{2}\right)}{1-\mathrm{t}_{2}}
\end{gathered}
$$

Since 'a' only uses constant values, from now on 'a' can be treated as a constant value. Proceeding with (4):

$$
\begin{gathered}
\mathrm{t}_{2}=\frac{\mathrm{b} * \beta_{1,2}+\beta_{1,2} * \overline{\mathrm{F}}_{1}\left(\mathrm{t}_{1}\right)}{\mathrm{b} * \beta_{1,2}+\beta_{1,2}} \\
\mathrm{t}_{2}=\frac{\mathrm{b}+\overline{\mathrm{F}}_{1}\left(\mathrm{t}_{1}\right)}{\mathrm{b}+1} \\
\mathrm{t}_{2} * \mathrm{~b}+\mathrm{t}_{2}-\mathrm{b}=\overline{\mathrm{F}}_{1}\left(\mathrm{t}_{1}\right) \\
\mathrm{b} *\left(\mathrm{t}_{2}-1\right)+\mathrm{t}_{2}=\overline{\mathrm{F}}_{1}\left(\mathrm{t}_{1}\right)
\end{gathered}
$$




$$
\mathrm{b}=\frac{\overline{\mathrm{F}}_{1}\left(\mathrm{t}_{1}\right)-\mathrm{t}_{2}}{\mathrm{t}_{2}-1}
$$

From Equation (5):

$$
\begin{gathered}
\frac{\mathrm{t}_{2}}{\mathrm{t}_{3}}=1+\frac{\beta_{2,3}}{\alpha_{2}+\beta_{1,2}} \\
\frac{\mathrm{t}_{2}}{\mathrm{t}_{3}}=1+\frac{\mathrm{k}}{\mathrm{b}+1} \\
\mathrm{k}=\left(\frac{\mathrm{t}_{2}}{\mathrm{t}_{3}}-1\right) *(\mathrm{~b}+1)
\end{gathered}
$$

Finally, from Equation (6):

$$
\begin{gathered}
\frac{\mathrm{t}_{3}}{\mathrm{t}_{2}}=\frac{\mathrm{c}+\mathrm{k} * \overline{\mathrm{F}}_{2}\left(\mathrm{t}_{2}\right)}{\mathrm{c}+\mathrm{k}} \\
\frac{\mathrm{t}_{3}}{\mathrm{t}_{2}} * \mathrm{c}+\frac{\mathrm{t}_{3}}{\mathrm{t}_{2}} * \mathrm{k}-\mathrm{c}=\mathrm{k} * \overline{\mathrm{F}}_{2}\left(\mathrm{t}_{2}\right) \\
\mathrm{c} *\left(\frac{\mathrm{t}_{3}}{\mathrm{t}_{2}}-1\right)=\mathrm{k} *\left(\overline{\mathrm{F}}_{2}\left(\mathrm{t}_{2}\right)-\frac{\mathrm{t}_{3}}{\mathrm{t}_{2}}\right) \\
\mathrm{c}=\mathrm{k} * \frac{\overline{\mathrm{F}}_{2}\left(\mathrm{t}_{2}\right)-\frac{\mathrm{t}_{3}}{\mathrm{t}_{2}}}{\frac{\mathrm{t}_{3}}{\mathrm{t}_{2}}-1}
\end{gathered}
$$

This concludes the calculation and now it is possible to find the buyer distribution over the network that would lead to the same pricing range and $\mathrm{CDF}$ in the original example by just setting a value for $\beta_{1,2}$. Note that there are many possible values for $\beta_{1,2}$, and each of them will lead to different utility levels. By choosing $\beta_{1,2}=150$, let see the value of the other markets that would be found by using the results that was calculated:

$$
\begin{aligned}
& \alpha_{1}=20.16233766 \\
& \alpha_{2}=0 \\
& \alpha_{3}=0.0455 \\
& \beta_{2,3}=195
\end{aligned}
$$

Note that those results are very close to the first example in Section 2. By calculating every market size as a ratio over one of them (in this case every market size was being calculated over $\beta_{1,2}$ ) it is possible verify, for $\mathrm{T}$ being the total of buyers that will be distributed over the structure:

$$
\begin{gathered}
\alpha_{1}+\alpha_{2}+\alpha_{3}+\beta_{1,2}+\beta_{2,3}=\mathrm{T} \\
\mathrm{a} * \beta_{1,2}+\mathrm{b} * \beta_{1,2}+\mathrm{c} * \beta_{1,2}+\mathrm{k} * \beta_{1,2}=\mathrm{T}
\end{gathered}
$$




$$
\beta_{1,2}=\frac{\mathrm{T}}{\mathrm{a}+\mathrm{b}+\mathrm{c}+\mathrm{k}}
$$

Similar reasoning can be applied for other networks. It is worth noting that the price and CDF values have been rounded at the beginning of this section, thus the approximated results for each market share.

\section{EXPANDED BERTRAND NETWORK}

To show what is willing to achieve, consider the following Figure.

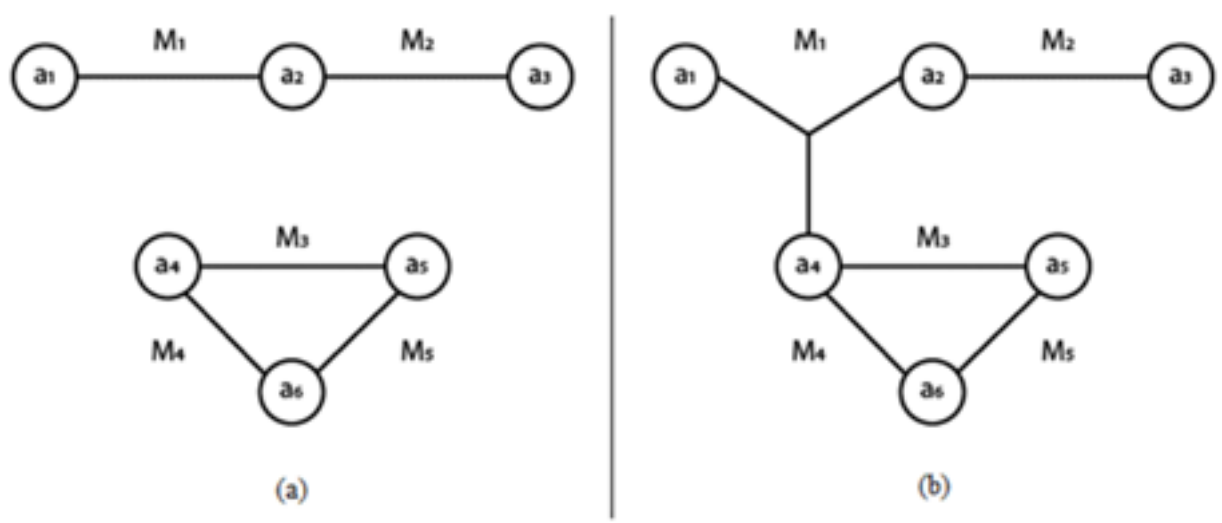

Figure 5 - Two connected components of the hypergraph in (a) representing two different market networks and (b) an expansion attempt of the firm $f_{4}$ to join the market share $M_{1}$.

First, it is stated that any market which is being shared for more than two firms are called oligopoly shared market. The meaning of $N(\mathrm{i})$ has changed to be the set of shared markets that are being shared to exactly 2 vendors. Now the Equation (2) is expanded to one form that considers the mix of duopolies and oligopolies.

$$
u_{i}(x)=x *\left(\alpha_{i}+\sum_{k \in N^{o}(i)} \beta_{k} * \sigma_{-i, k}(x)+\sum_{j \in N(i)} \beta_{i, j} * \bar{F}_{j}(x)\right)
$$

Where $\mathrm{N}^{\mathrm{o}}(\mathrm{i})$ is the set of the neighboring oligopoly shared markets of $i, \beta_{\mathrm{k}}$ is the size of the oligopoly shared market $\mathrm{k}$ and $\sigma_{-i, k}(x)$ represents some combination of the CDFs of all vendors that are participating in the oligopoly shared market $\mathrm{k}$ excluding the firm $\mathrm{i}$, as a subset of $[0,1]$. Essentially $\sigma_{-i, k}(x)$ tries to represent the combination of the pricing strategy of all competitors of $\mathrm{i}$ in the oligopoly $\mathrm{k}$. 
That said, the attempt to define the aggregated function of CDFs for oligopoly markets is shown below. To let the utility function be linear (like in the original model), let the aggregated function be the average sum of all the CDFs. Consider any oligopoly $k$ with $n$ firms and let $\mathrm{H}(\mathrm{k}, \mathrm{y})$ be a hash function that returns the index of the $\mathrm{y}$-th firm in that oligopoly $\mathrm{k}$, for $1 \leq \mathrm{y} \leq \mathrm{n}$ :

$$
\sigma_{-i, k}(x)=\frac{\sum_{\mathrm{y}=1}^{\mathrm{n}} \overline{\mathrm{F}}_{\mathrm{H}(\mathrm{y})}(\mathrm{x})-\bar{F}_{H(i)}(x)}{n-1}
$$

For the sake of simplicity, $\mathrm{k}$ has been omitted from $\mathrm{H}(\mathrm{k}, \mathrm{y})$. The belief that, in any oligopoly with at least 2 firms that has a captive market, Lemma 4.2 from Babaioff et al (2013, p. 9) does not apply is shown below.

Conjecture 1. Fix any network composed by one oligopoly shared market with at least 2 firms that has a positive captive market. There exist more than one firm that does choose 1 with positive probability.

Assume that Lemma 4.2 does apply. Sort the firms and label them from 1 to $\mathrm{n}$ such as $\alpha_{1} \geq \alpha_{2}>$ $\alpha_{3} \ldots \geq \alpha_{n} \geq 0$. Then, if $f_{1}$ has an atom at 1 , the following holds:

$$
\sigma_{-1}(1)=0
$$

Then:

$$
\begin{gathered}
\sigma_{-1}(1)=\frac{\sum_{j=2}^{n} \bar{F}_{j}(1)}{n-1} \\
\sum_{j=2}^{n} \bar{F}_{j}(1)=0
\end{gathered}
$$

Which is true since none of the firms has an atom at 1 . Therefore, for every $1<\mathrm{i} \leq \mathrm{n}$ :

$$
\begin{gathered}
\sigma_{-\mathrm{i}}(1)=\frac{\bar{F}_{1}(1)+\sum_{\mathrm{j}=2}^{\mathrm{n}} \overline{\mathrm{F}}_{\mathrm{j}}(1)-\bar{F}_{i}(1)}{\mathrm{n}-1} \\
\sigma_{-\mathrm{i}}(1)=\frac{\bar{F}_{1}(1)}{\mathrm{n}-1}
\end{gathered}
$$

Thus, For every $1<\mathrm{i} \leq \mathrm{n}$ :

$$
\mathrm{u}_{\mathrm{i}}(1)=\alpha_{\mathrm{i}}+\beta * \sigma_{-\mathrm{i}}(1) \Rightarrow \mathrm{u}_{\mathrm{i}}(1)=\alpha_{\mathrm{i}}+\beta * \frac{\bar{F}_{1}(1)}{\mathrm{n}-1}
$$

For the firm $n$ there exist a minimum price $t_{2}$ that allows mixing, thus the following must hold:

$$
\begin{gathered}
\mathrm{u}_{\mathrm{n}}(1)=\mathrm{u}_{\mathrm{n}}\left(\mathrm{t}_{2}\right) \\
\alpha_{\mathrm{n}}+\beta * \frac{\bar{F}_{1}(1)}{\mathrm{n}-1}=\mathrm{t}_{2} *\left(\alpha_{\mathrm{n}}+\beta * \frac{\bar{F}_{1}\left(t_{2}\right)}{\mathrm{n}-1}\right)
\end{gathered}
$$




$$
\begin{gathered}
\alpha_{\mathrm{n}}+\beta * \frac{\bar{F}_{1}(1)}{\mathrm{n}-1}=\mathrm{t}_{2} *\left(\alpha_{\mathrm{n}}+\beta * \frac{1}{\mathrm{n}-1}\right) \\
\mathrm{t}_{2}=\frac{\alpha_{\mathrm{n}}+\beta * \frac{\bar{F}_{1}(1)}{\mathrm{n}-1}}{\alpha_{\mathrm{n}}+\beta * \frac{1}{\mathrm{n}-1}}
\end{gathered}
$$

Every firm that will mix must be mixing at the same interval $\left[t_{2}, 1\right]$, so none of them can deviate and ask for a price that will allow him to win the shared market with probability one (Babaioff et al, 2013; Guzmán, 2011).

$$
\begin{gathered}
\mathrm{t}_{2}=\frac{\alpha_{\mathrm{i}}+\beta * \frac{\bar{F}_{1}(1)}{\mathrm{n}-1}}{\alpha_{\mathrm{i}}+\beta * \frac{1}{\mathrm{n}-1}} \\
\frac{\alpha_{\mathrm{n}}+\beta * \frac{\bar{F}_{1}(1)}{\mathrm{n}-1}}{\alpha_{\mathrm{n}}+\beta * \frac{1}{\mathrm{n}-1}}=\mathrm{t}_{2}=\frac{\alpha_{\mathrm{i}}+\beta * \frac{\bar{F}_{1}(1)}{\mathrm{n}-1}}{\alpha_{\mathrm{i}}+\beta * \frac{1}{\mathrm{n}-1}}
\end{gathered}
$$

This is only possible if $a_{n}=a_{i}$ for every $i$, contradicting the assumption that each firm may have different sizes of captive markets. This suggests that another firm might be choosing the price of 1 (which would lead to $\sigma_{-i}(1)>0$ for another $\mathrm{i}>1$ ), or some firm is choosing the price of 1 with negative probability, from the equality in Equation (8).

This concludes the belief that Lemma 4.2 must be reworked, in addition to another prof by Guzmán (2011) that asserted that the duopoly model is the solution of the oligopoly model, but with a different aggregated function.

\section{CONCLUSIONS AND FUTURE WORK}

This paper has presented one way to use the model for guessing the distribution of buyers over one competition network. As stated before, the information that can be gather from the proposed attempt to show how this model is very important and can be useful in analyzing the attempt of one company to join in another market.

It is now needed to apply this to a real case, detailing how it would be possible to identify the CDF for each firm at every boundary point of firms support. It is also needed to provide one formal prof for the Conjecture 1 (if true). 


\section{REFERENCES}

Abolhassani, M., Bateni, M. H., Hajiaghayi, M., Mahini, H., \& Sawant, A. (2014). Network cournot competition. Lecture Notes in Computer Science, (pp. 15-29).

Babaioff, M., Blumrosen, L., \& Nisan, N. (2016). Networks of Complements. The 43rd International Colloquium on Automata, Languages and Programming (ICALP). Retrieved from https://www.microsoft.com/en-us/research/publication/networks-of-complements/

Babaioff, M., Lucier, B., \& Nisan, N. (2013, June). Bertrand networks. Proceedings of the Fourteenth ACM Conference on Electronic Commerce. doi:10.1145/2482540.2482564

Babaioff, M., Nisan, N., \& Paes Leme, R. (2014). Price Competition in Online Combinatorial Markets. Proceedings of the 23rd International Conference on World Wide Web (pp. 711-722). Seoul, Korea: ACM. doi:10.1145/2566486.2568016

Barquin, J., \& Vazquez, M. (May de 2008). Cournot Equilibrium Calculation in Power Networks: An Optimization Approach With Price Response Computation. IEEE Transactions on Power Systems, 23(2), 317-326. doi:10.1109/TPWRS.2008.919198

Bimpikis, K., Ehsani, S., \& Ilkiliç, R. (2014). Cournot Competition in Networked Markets. Proceedings of the Fifteenth ACM Conference on Economics and Computation (pp. 733-733). Palo Alto, California, USA: ACM. doi:10.1145/2600057.2602882

Bose, S., Cai, D. W., Low, S. H., \& Wierman, A. (2014). The role of a market maker in networked cournot competition. arXiv: Computer Science and Game Theory, 4479-4484. Retrieved 5 10, 2018, from http://dblp.uni-trier.de/db/journals/corr/corr1701.html

Bose, S., Cai, D. W., Low, S., \& Wierman, A. (2014). The role of a market maker in networked cournot competition. 53rd IEEE Conference on Decision and Control, (pp. 4479-4484). doi:10.1109/CDC.2014.7040088

Cai, D., Bose, S., \& Wierman, A. (2017). On the role of a market maker in networked cournot competition. Obtido de https://arxiv.org/abs/1701.08896

Guzmán, C. L. (2011). Price competition on network. Banco de México.

Jing-Yuan, W., \& Smeers, Y. (1999). Spatial Oligopolistic Electricity Models with Cournot Generators and Regulated Transmission Prices. Operations Research, 47(1), 102-112. doi:10.1287/opre.47.1.102

Kasbekar, G. S., \& Sarkar, S. (January de 2012). Spectrum Pricing Games with Spatial Reuse in Cognitive Radio Networks. IEEE Journal on Selected Areas in Communications, 30(1), 153-164. doi:10.1109/JSAC.2012.120114

Motalleb, M., Eshraghi, A., Reihani, E., Sangrody, H., \& Ghorbani, R. (2017). A game-theoretic demand response market with networked competition model. 2017 North American Power Symposium (NAPS) (pp. 1-6). Morgantown, WV, USA: IEEE. doi:10.1109/NAPS.2017.8107253

Scheinkman, D. M., \& A., J. (1983). Quantity Precommitment and Bertrand Competition Yield Cournot Outcomes. The Bell Journal of Economics, 14, 326-337. doi:10.2307/3003636

Yao, J., Oren, S. S., \& Adler, I. (2004). Computing Cournot equilibria in two settlement electricity markets with transmission constraint. 37th Annual Hawaii International Conference on System Sciences. doi:10.1109/HICSS.2004.1265176 